\title{
Interactive Model of Disaster Risk \& Disaster Management: The Egg Model
}

\author{
Gholamreza Poorheidari ${ }^{1,2}$ (D) , Mahdi Mashhadi Akbar Boojar ${ }^{1}$ (D) and Ahmad Soltani ${ }^{2,3, *}$ (iD) \\ 1 Department of Pharmacology and Toxicology, Faculty of Pharmacy, Baqiyatallah University of Medical Sciences, Tehran, Iran \\ 2 Assistant Professor, Research Center for Emergency and Disaster Resilience, Red Crescent Society of the Islamic Republic of Iran, Tehran, Iran \\ ${ }^{3}$ Assistant Professor, Iran-Helal Institute of Applied-Science and Technology, Red Crescent Society of the Islamic Republic of Iran, Tehran, Iran \\ * Corresponding author: Ahmad Soltani, Research Center for Emergency and Disaster Resilience, Red Crescent Society of the Islamic Republic of \\ Iran, Tehran, Iran. Tel: 00982188974894; Email: soltani.amd@gmail.com
}

Received 2020 May 10; Revised 2020 July 11; Accepted 2020 July 21.

\begin{abstract}
Background: A conceptual model is always a suitable way to show the relationship between the different components of a process or among different processes. In the field of incident management, there are several models. However, there is almost no simple, natural, conceptual model to show the relationship between disaster risk management.

Methods: Because of the need for the development of a simple model that can quickly and at a glance relate the overall steps and components of the risk management process and various phases of disaster management, this model has been invented based on the evaluation of previous studies and reviewing current literature as well as refining the research and innovation done by the authors.

Results: In this article, a new model, which is called the Egg model, including the shell, the white (albumen) and the yellow (yolk) parts, is introduced. In which, risk management includes three steps. The first step is the assignment of a body, either a person, team or organization, as responsible (the resembling the shell). In the second step, the body does the assessment of the risk (resembling the white part). Risk assessment, on its own, includes risk identification, risk analysis, and risk evaluation. Finally, (resembling the yellow part), treatment of the risk(s) is begun which includes, prevention and mitigation, and preparedness before the disaster and, response and recovery after the disaster occurrence. Obviously, without an intact shell, the whole egg (albumen and yolk) will decay and all resources will be lost. Also without assessment of the risks, proper and effective management of the disaster is almost impossible. The third step of the risk management, the risk treatment, is in fact the disaster management.

Conclusion: This simple model shows the relationship between risk management and risk treatment. Although this model may have oversimplified the process of Risk Management, it helps to create a unique overview and understanding for almost everyone.
\end{abstract}

Keywords: Conceptual model, Risk management, Disaster management, The egg model

\section{Background}

Providing an interactive conceptual model between disaster and risk management can be useful for multiple reasons (1). Some of the benefits of such a model include: a model that distinguishes between important elements, simplifies the understanding of a complex event or process; comparing actual situations with a conceptual model leads to a better understanding of the current condition and facilitates the process of planning and completing risk and disaster management programs (2). The availability of a simple and interactive model for risk and risk treatment is a considerable point in the quantification of emergency state (3). A model designed for risk and disaster management (risk treatment) will lead to a common understanding of almost all the factors involved and thus enhances the centralization and convergence of all relief efforts in all stages (especially the response and recovery phase) (4).

Therefore, it is clear that a very simple and welldefined model will be very useful in understanding of the interaction of risk and disaster management and their relationship to each other and will help the efforts made in this area to be performed effectively. In the past, and sometimes in today's writings and commentaries, when one person speaks of disaster management, the minds turn to the response phase, as if it were only at the time of the incident that it should be managed. But we all agree that risk treatment starts with prevention and mitigation before it happens and continues with the preparation for an appropriate response to the emergency stage. In the event of a disaster, the emergency response needs are addressed through a number of measures, and after the response phase, recovery efforts should be performed including physical and mental rehabilitation and infrastructure reconstruction and facility restoration which, overall, called a disaster management cycle $(5,6)$.

Although there are various views on the components of the cycle and the precedence and latency of its phases, its generality, as it was drawn, is in the consensus of all managers and researchers in the field of disaster management (7). It is true that prevention and mitigation must be prioritized, and in fact, the prevention and reduction of impacts must be continually addressed in all programs and such action must be taken on a continuous basis, but the question is: for which sort of risk(s), prevention and mitigation measures should be considered? This important question arises here and the answer to that is one step before the management of a disaster. It is a critical step: the risk assessment (8). The risk assessment step itself, however, involves a process of several phases that will be later discussed in this 
article. It should be emphasized here that neglecting this step in dealing with disaster management is relatively common and this is why communities come across unexpected incidents and disasters.

One more important question still remains here that who is responsible for assessing (identifying, analyzing and evaluating) the risk of incidents and disasters? Therefore, a person, team, entity or organization with sufficient authority and expertise to assess risk(s) should be assigned and required to draw a risk map and to do the emergency planning for the various hazardous situations in the areas under control, and accordingly preventive measures and preparative responses be considered and implemented (9). Therefore, assigning a responsible entity or organization for risk assessment is the first step of risk management that is of particular importance (10).

This paper presents the above concepts in a completely simple, clear and at the same time practical model, in order to facilitate the overall understanding of risk management and its relationship with disaster management to not only all managers and researchers in the field of risk and also disaster management, but also every member of the community.

\section{Objectives}

Since there is a need for the cooperation of officials and citizens to achieve a resilient community, the necessity to introduce a simple model that can easily explain the concept of risk and disaster management to all citizens has become critical which is aimed in this article (9).

\section{Methods}

Because of the need for the development of a simple model that can quickly and at a glance relate the overall steps and components of the risk management process and various phases of disaster management, this model has been invented based on the evaluation of previous studies and reviewing current literature as well as refining the research and innovation done by the authors. The model was also developed based on the experiences and knowledge of the authors.

Although different models are presented today to explain disaster risk management, due to the many parameters that are included, they are not easy to understand for everyone (including the general public, managers and non-professional experts), and therefore cannot always be useful and applicable. However, the importance and usefulness of those models remain in place in terms of the various factors affecting risk treatment process $(4,11,12)$. Therefore, the model presented in this paper is compatible with existing models plus the conceptual and functional relevance of risk and disaster management. This very simple conceptual model is called the Egg Model.

\section{Results}

Our simple, innovative and novel model (the Egg Model) is here illustrated and explained in Figure 1. The most innovative point of this model is the resemblance of whole process of disaster risk management to an egg structure which is familiar to everyone and, therefore, is very helpful for being easily understood.

This novel and innovative model is called the Egg model and includes: the shell, the white (albumen) and the yellow (yolk) parts. Risk management includes similarly three steps. The first step is the assignment of a body, either a person, team or organization, as responsible (the shell). In the second step, the responsible body assesses the risks (the white part). In the final and third step (equals to the yellow part, the yolk), treatment of the $\operatorname{risk}(\mathrm{s})$ is begun which includes, prevention and mitigation, and preparedness before the disaster and, response and recovery after the disaster occurrence. Obviously, without an intact shell, the whole egg (albumen and yolk) will decay. The designation of the responsible organization or individual is the most primitive and initial step in the risk management process and all

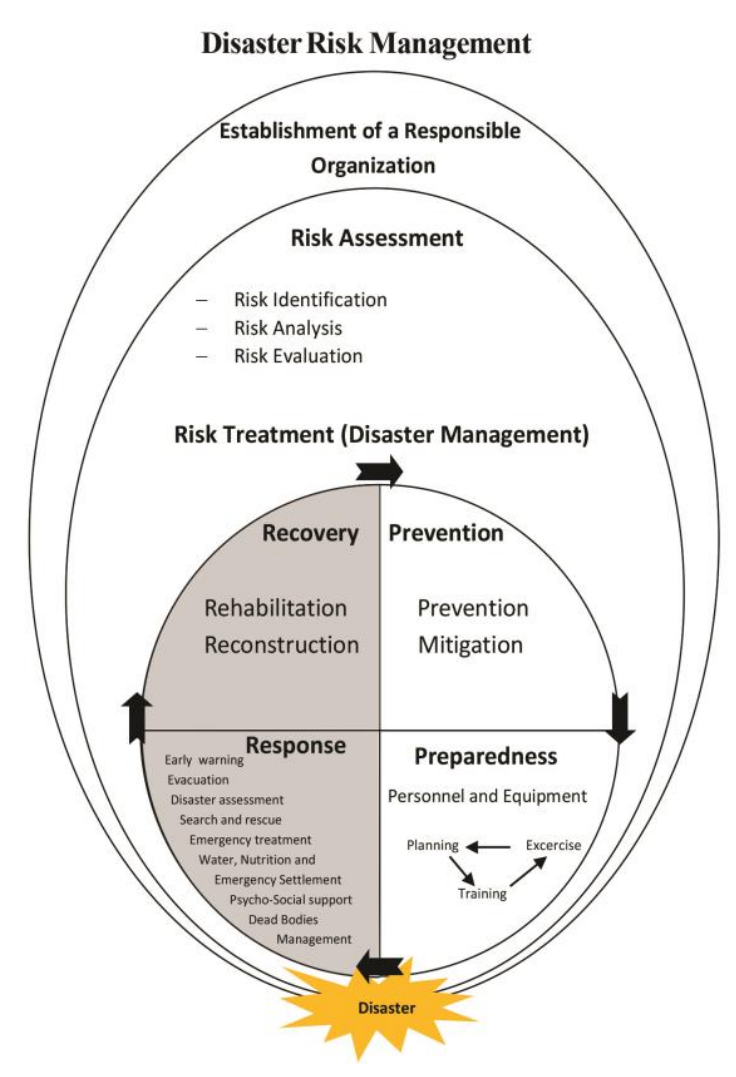

Figure 1. Interactive disaster risk and disaster management model (Egg Model) 
other steps must be performed under the leadership, guidance, and coordination of this responsible body. One of the tasks of the responsible organization or person is to implement the second step of risk management which is the assessment of risks. Risk assessment, on its own, includes risk identification, risk analysis, and risk evaluation. Risk assessment should also be carried out before and during all phases of the third step which is risk treatment or disaster management. Without the necessary inspection and implementation of appropriate measures, new incidents and disasters may arise and add to the extent of current ones. Finally, the third step is risk treatment, which includes the components of prevention (including mitigation), preparedness, response, and recovery. Although the various components of disaster management phase are listed in different sources from three to eight components, this model lists four components. The first and second components that must be implemented before a disaster occurs are prevention and preparedness. These actions should take place at a time when the incident has not occurred (the day). While the third and fourth components, (response and recovery), take place during and after the disaster when the disaster is being resolved (the night).

\subsection{Three steps of the risk management process in more detail}

Here, the three steps which are the basis of the presented model will be explained in more detail. In general, the risk management process has three main steps:

Step one: Establishment of a responsible entity or organization

Step two: Assessment of the risk(s)

Step three: Treatment of risk or management of disaster (6).

\subsubsection{Step One: assigning an entity or organization in charge}

Establishing an institution that is responsible for the task and has the necessary capability, expertise, authority, and credibility is an essential and important step. The entity or organization responsible for the protection of natural resources (including the environment) and man-made resources, both industrial and non-industrial, should be integrated (13). An organization responsible for the protection of resources and management of disasters must not only achieve relative self-reliance in managing certain disasters and emergencies but must also be adequately organized and interoperable with all organizations and agencies to manage emergencies and potentially critical, interactive and complex situations. In emergency situations, decision-making is difficult and decisions need to be made in a short time, and this can only be done properly by trained managers with the necessary attributes and authority $(6,7)$.

\subsubsection{Step Two: Assessment of the risks and drawing the risk map}

The second step involves assessing the risks which, in turn, involves three stages: 1) identifying the risks, 2) analyzing the vulnerability of the community in exposure to possible hazards and threats, and 3) evaluation and prioritizing risks to manage them (14).

Identifying the risk of hazards and threats includes: using past experiences and also historical information in a specific area on the one side and foreseeing the future and scientific prediction of probable exposure to the hazards and threats, on the other side.

Natural hazards include earthquakes, floods, landslides, colds and frosts, intense heat and the like, and man-made hazards include environmental pollution, explosions, toxic leakages, traffic hazards and the like. Secondary hazards include those that arise after a primary hazard, such as fire, landslides and dam breaks after an earthquake.

After identifying the risks, one should examine and estimate the extent of risks, the probability of incidents, and the extent of the damage and the consequences of their occurrence. The extent of damage and destruction or the consequences of a potential incident is, in fact, directly related to the vulnerability of the community at risk.

In the third and final stage of the risk assessment is evaluating and prioritizing probable events and exposure to the risks for management based on capabilities, financial affordability, level of community development, general policies, the political and economic situation. Therefore, prior to any action, a risk map of the potential hazards should be prepared and the extent of their occurrence and priority of treatment, as well as the manner of dealing with them, should be specified (15).

\subsubsection{Step Three: Risk treatment or disaster management}

The third and final step is the treatment of the risks which include prevention and mitigation, preparedness, response, and recovery in an allhazards approach and based on the previous step findings and drawn risk maps, considering the community's capabilities.

Prevention: Prevention is a set of measures that allows for adaptation to risks without causing an incident, emergency or disaster. Accurate implementation of preventive measures plays an important role in preserving community resources. Of course, efforts and costs for prevention are usually not appreciated, as they prevent incidents, emergencies, and disasters that have not occurred and therefore have not been seen and have not 
affected the community (16).

Mitigation (which is usually included in the prevention phase), is a set of measures that, while not preventing the occurrence of an incident or exposure to hazards, reduce the destructive effects of incidents. Some hazards, such as earthquakes, cannot be prevented, but mitigation measures are crucial in reducing casualties. Of course, these actions are also usually overlooked, since destructions have not happened and the value of these actions has not been clearly seen, and their status and importance remain hidden (with neglect).

Preparedness: Preparedness refers to a set of actions that respond to the needs of emergencies and disasters such as facilities, equipment, and trained human resources, along with planning, organizing, training, and maneuvering (17).

A set of preparedness measures for response operation, such as equipping, organizing, and training, and maneuvering based on possible scenarios of incidents or disasters, or in response to real-life events, is called the preparedness. Planning, training, and maneuvering which forms the preparedness cycle increase the actual preparedness.

In planning what is more important than having a written plan, is the full implementation of the planning process with the participation of all stakeholders, including agencies, NGOs, and the general public representatives. Implementation of the planning process will result in coordination, synergy, speed of operation, etc. in all areas of action. Training and organization to acquire the skills to make effective use of equipment and facilities and the ability to deal with specific situations of disaster and to work in a functioning team are among the essentials for a successful operation. Having different banks of data and information is also a necessity for effective planning.

Response: Response includes an extensive set of measures. The first measure in the response phase is a rapid and clear alert to the community members. Responding effectively to emergencies and disasters, including a number of core measures such as the early warning, emergency evacuation of people, initial assessment of casualties and physical damages, search and rescue, emergency treatment and transportation of the injured, relief including safe water and emergency food and settlement, psychosocial support, management of humanitarian aids, and also management of the volunteers, and finally management of the dead bodies (18).

Recovery: Recovery means a return of the community to a pre-disaster condition; the situation prior to the disaster occurrence. Recovery, in addition to rebuilding infrastructure, critical facilities, lifelines, and the physical and mental rehabilitation of disadvantaged people; it also includes reconstruction of the identity of the affected community. Physical rehabilitation and recovery of those who have lost part of their ability or organs are very important to keep pace with mental rehabilitation to minimize injuries and restore or enhance one's ability. Obviously, if the recovery plan is prepared in advance, preventive measures will be well implemented and recovery will be possible in a much shorter time $(19,20)$.

The management of resources, communications, security, and police are some of the things that are not mentioned in this conceptual model for the sake of simplicity that can be learned and adjusted within the context of the above model after a general understanding of the key concepts.

\section{Discussion}

Today, global strategies for disaster management focus on risk reduction $(21,22)$. Because it not only reduces costs, it also makes managing risk much easier in the early stages. However, reducing risk avoids events and disasters that are never seen because they do not occur. Therefore, it requires additional efforts to implement the risk reduction measures in the community (including both officials and people) (23).

One of the most effective efforts in this field is providing a conceptual model that shows the relationship of the response phase with the other phases of disaster management cycle including prevention, preparedness, response and recovery, and on the other hand to map the relationship of risk treatment cycle with different steps of risk management.

As suggested by the proposed model, identifying the individual or entity and assigning for the responsibility of protecting the community against various hazards is the first and most important step of risk management (24). Obviously, a person or entity in charge, with the ability, authority, credibility, experience, and expertise is required to perform the assigned missions. Therefore, the selection and assignment of a responsible person or entity with the required characteristics is one of the most important issues in any community, from the family as the smallest social unit to the whole country and the nation (25).

Identifying the risk of the hazards and analyzing and weighing and then prioritizing them according to the different conditions of society for dealing with and managing them is not properly performed, because this step is generally less considered. Usually, the community (including officials and people) goes directly into the third step of risk management, which is risk treatment. At best, those threats that have repeatedly affected the community have been addressed, while development of the countries, as well as the climate change and also technological advances, are always imposing new risks and threats on the community. Therefore, 
reviewing and monitoring the hazards and their risks is a constant need to be acknowledged at regular intervals and to implement preventive and other risk reductive measures appropriate to their possible impacts $(26,27)$.

The link between the risk treatment measures, namely prevention, preparedness, response, and recovery, although always shown in a cycle and it helps to understand, but the other two risk management steps (the first and the second) should also be considered. Although some models specifically emphasize the importance of preventive measures before the disasters and incidents, while preventive measures are also important in the preparedness phase. Furthermore, ignoring the risk of response measures can increase the damage, and may even impose new and additional damage to the disaster-stricken community $(28,29)$.

\section{Conclusion}

Consequently, it is concluded that this simple and quickly understandable conceptual model, (the Egg Model) while not fully elaborating all the detail of risk and disaster management, can provide a common and general understanding for all members of a community (both people and the officials). In addition, this model is useful for understanding the whole risk management process and in all natural and man-made disasters. This fact is acknowledged by understanding that the third step of risk management is consistent with all disaster management measures (whether preventive or otherwise). In other words, one of the point that is emphasized in this model is the relationship between disaster management and risk management, and from the perspective of this model, disaster management is the third and final step of the risk management process. The whole process of risk management which three main steps have resembled the structure of an egg (the shell, the white and the yellow) is quite familiar and understandable to everyone and this is the key point and more innovative part the model presented in this article.

\section{Footnotes}

Conflict of Interests: The authors declare that there is no conflict of interest regarding the publication of this paper.

\section{References}

1. Kelly C. Simplifying disasters: developing a model for complex non-linear events. Austral J Emerg Manag. 1999;14(1):25-7.

2. Heath RL, O'Hair HD. Handbook of risk and crisis communication. London: Routledge; 2010.

3. Cimellaro GP, Fumo C, Reinhorn AM, Bruneau M. Quantification of disaster resilience of health care facilities. Buffalo, NY: MCEER; 2009.

4. Asghar S, Alahakoon D, Churilov L. A comprehensive conceptual model for disaster management. J Humanit Assistance. 2006;1360(0222):1-5.

5. Harrison SE, Johnson PA. Crowdsourcing the disaster management cycle. Int J Inform Syst Cris Resp Manag. 2016;8(4):17-40. doi: 10.4018/IJISCRAM.2016100102.

6. Valadbeigi B, Poorheidari G. Disaster planning. Tehran: Iranian Scientific Association for Disaster Management; 2015.

7. Poorheidari G, Valadbeigi B. Textbook of Integrated and Comprehensive Disaster Management. Tehran: Iranian Scientific Association for Disaster Management; 2012.

8. Boin A, Stern E, Sundelius B. The politics of crisis management: Public leadership under pressure. Cambridge: Cambridge University Press; 2016.

9. Poorheidari G, Valadbeigi B. A Guide to site emergency planning. Tehran: Iranian Scientific Association for Disaster Management; 2014.

10. Sutton J, Tierney K. Disaster preparedness: concepts, guidance, and research. Colorado: University of Colorado; 2006. P. 1-41.

11. Cyganik KA. Disaster preparedness in Virginia Hospital CenterArlington after Sept 11, 2001. Disaster Manag Response. 2003; 1(3):80-6. doi: 10.1016/s1540-2487(03)00048-8. [PubMed: 12888746].

12. Center Asian Disaster Preparedness. Building disaster risk reduction in Asia: a way forward: ADPC looks ahead to 2015. Bangkok, Thailand: Asian Disaster Preparedness Center; 2000.

13. Pradhananga R, Mutlu F, Pokharel S, Holguín-Veras J, Seth D. An integrated resource allocation and distribution model for pre-disaster planning. Comp Ind Eng. 2016;91:229-38. doi: 10.1016/j.cie.2015.11.010.

14. Albtoush R, Dobrescu R, Ionescou F. A hierarchical model for emergency management systems. Univ Politehnica Bucharest Sci Bull Ser C. 2011;73(2):53-62.

15. Sahebjamnia N, Torabi SA, Mansouri SA. Integrated business continuity and disaster recovery planning: towards organizational resilience. Eur J Operat Res. 2015;242(1):26173. doi: 10.1016/j.ejor.2014.09.055.

16. Zhai Y, Chen S, Ouyang Q. GIS-based seismic hazard prediction system for urban earthquake disaster prevention planning. Sustainability. 2019;11(9):2620. doi: 10.3390/su11092620.

17. Cole MA, Elliott RJ, Okubo T, Strobl E. Pre-disaster planning and post-disaster aid: examining the impact of the Great East Japan earthquake. Int J Disaster Risk Red. 2017;21:291-302. doi: 10.1016/j.ijdrr.2016.12.015.

18. Wang L, Yang L, Gao Z, Li S, Zhou X. Evacuation planning for disaster responses: a stochastic programming framework. Transp Res part C Emerg Technol. 2016;69:150-72. doi: 10.1016/j.trc.2016.05.022.

19. Ahmadi A, Bazargan-Hejazi S. 2017 Kermanshah earthquake; lessons learned. J Inj Violence Res. 2018;10(1):1-2. doi: 10.5249/jivr.v10i1.1049. [PubMed: 29374766].

20. Mousavi G, Khorasani-Zavareh D, Ardalan A, Khankeh H, Ostadtaghizadeh A, Kamali M, et al. Continuous post-disaster physical rehabilitation: a qualitative study on barriers and opportunities in Iran. J Inj Violence Res. 2019;11(1):35-44. doi: 10.5249/jivr.v11i1.1036. [PubMed: 30635998].

21. Marcus O. A conceptual framework for risk reduction. World Conference of Disaster Reduction, Kobe, Japan; 2005.

22. Pupavac V. Global disaster management and therapeutic governance of communities. Dev Dialogue. 2012;58:81-97.

23. Sinha DK. Natural disaster reduction: South East Asian realities, risk perception and global strategies. New York: Anthem Press; 2007.

24. Comfort LK. Risk, security, and disaster management. Annu Rev Polit Sci. 2005;8:335-56. doi: 10.1146/annurev.polisci. 8.081404.075608.

25. Palttala P, Boano C, Lund R, Vos M. Communication gaps in disaster management: Perceptions by experts from governmental and non-governmental organizations. J Conting Cris Manag. 2012;20(1):2-12. doi: 10.1111/j.1468-5973. 2011.00656.x.

26. Mechler R, Bouwer LM, Linnerooth-Bayer J, HochrainerStigler S, Aerts JC, Surminski S, et al. Managing unnatural disaster risk from climate extremes. Nature Climate Change. 2014;4(4):235-7. 
27. Tingsanchali T. Urban flood disaster management. Proc Eng. 2012;32:25-37. doi: 10.1016/j.proeng.2012.01.1233.

28. Khan H, Vasilescu LG, Khan A. Disaster management cycle-a theoretical approach. J Manag Market. 2008;6(1):43-50.
29. Coetzee C, Van Niekerk D. Tracking the evolution of the disaster management cycle: a general system theory approach. J Disaster Risk Stud. 2012;4(1):1-9. 